\title{
SUBSTRATOS E NÍVEIS DE ÁGUA NO POTENCIAL GERMINATIVO DE SEMENTES DE UVAIA ${ }^{1}$
}

\author{
Silvana de Paula Quintão Scalon ${ }^{2}$ e Tatiane Sanches Jeromine ${ }^{2}$
}

\begin{abstract}
RESUMO - Objetivou-se neste trabalho avaliar o substrato e a disponibilidade de água no potencial germinativo das sementes de uvaia (Eugenia pyriformis). Os substratos avaliados foram: areia (A), latossolo + areia $(\mathrm{L}+\mathrm{A})(1: 1)$, latossolo + areia + cama de frango semidecomposta $(\mathrm{L}+\mathrm{A} 1+\mathrm{CF})(1: 1: 0,5)$, latossolo + areia + cama de frango semidecomposta $(\mathrm{L}+\mathrm{A} 2+\mathrm{CF})(1: 2: 0,5)$, latossolo + Bioplant ${ }^{\circledR}(\mathrm{L}+\mathrm{B})(1: 1)$ aliados aos seguintes níveis de irrigação 25, 50, 75 e $100 \%$ da capacidade de retenção de água. As maiores porcentagens de emergência e melhor crescimento de plântulas foram observados no substrato latossolo + areia + cama de frango (1:2:0,5), na capacidade de retenção de água de 50\%.
\end{abstract}

Palavras-chave: Myrtaceae, Ecofisiologia, Cerrado.

\section{SUBSTRATE AND WATER LEVELS ON THE GERMINATIVE POTENTIAL OF SEEDS OF UVAIA}

\begin{abstract}
The objective of this study was to evaluate the substrate and water availability on germinative pontential of Uvaia (Eugenia pyriformis) seeds. The substrates evaluated were the following: Sand (S), Latosol + sand $(\mathrm{L}+\mathrm{S})(1: 1)$, Latosol + sand + semi-decomposed chicken litter (L + S1 + CL ) (1:1:0.5), Latosol + sand + semi-decomposed chicken litter $(\mathrm{L}+\mathrm{S} 2+\mathrm{CL})(1: 2: 0.5)$, Latosol + Bioplant ${ }^{\circledR}+(\mathrm{L}+\mathrm{B})(1: 1)$ joined to the following water levels: $25,50,75$ and $100 \%$ the ability to retain water. The highest percentage of emergence and the best seedling growth were observed in substrates Latosol + sand + chicken litter (1:2:0.5) and water retention capacity of $50 \%$.
\end{abstract}

Keywords: Myrtaceae, Ecophysiology, Cerrado.

\section{INTRODUÇÃO}

O Cerrado é uma formação vegetal que predomina no Estado de Mato Grosso do Sul, pois ocupa cerca de $61 \%$ do seu território, no entanto grande parte dessas áreas não possui mais a cobertura vegetal original, atualmente ocupada por paisagens antrópicas (LEHN et al., 2008).

Diante da grande preocupação com a extinção das espécies nativas do Cerrado, os pesquisadores estão buscando técnicas de cultivo e produção de mudas dessas espécies, potencializando sua exploração. Assim, a utilização de forma sustentável das plantas nativas, principalmente as frutíferas, podem ser geradoras de renda para a população desse bioma (SCREMIN-DIAS, 2006).

Uma das opções de espécie nativa é a uvaia (Eugenia pyriformis), planta que mede entre 5 e $15 \mathrm{~m}$ de altura, cujos frutos são indeiscentes, carnosos, piriformes, pilosos e com coloração amarela e comestíveis, de sabor adocicado e acidulado, podendo ser utilizados na fabricação de suco, vinagre e vinho. As sementes têm tegumento de coloração castanha e cotilédones carnosos e justapostos, as quais, após a extração, se oxidam rapidamente (ANDRADE; FERREIRA, 2000;

\footnotetext{
${ }^{1}$ Recebido em 23.07.2012aceito para publicação em 20.12.2012

${ }^{2}$ Universidade Federal da Grande Dourados, Faculdade de Ciências Agrárias, Brasil. E-mail: <silvanascalon@ufgd.edu.br>e $<$ tati_jeromini@hotmail.com>.
} 
DELGADO; BARBEDO, 2007). Além disso, a maioria das espécies de E. pyriformis nativas do Brasil produz poucas sementes, geralmente uma ou duas, o que dificulta a produção de mudas em escala comercial (VENDRAME SILVA et al., 2005).

Assim, a escolha do substrato deve basear-se, entre outros fatores, no custo e na disponibilidade, de forma que várias misturas podem ser sugeridas para a produção de mudas, sendo as mais comuns o solo acrescido ou não de areia, misturas contendo húmus, casca de arroz carbonizada, esterco de galinha, palha de café, carvão vegetal e Bioplant ${ }^{\circledR}$.

As características físicas do substrato e as propriedades químicas são muito importantes, pois devem fornecer, durante a formação da muda, melhor aeração e permeabilidade, além de oxigênio e água para as sementes (RODRIGUES et al., 2007). Assim, o uso de substratos e recipientes adequados permite a obtenção de mudas mais vigorosas (REISSER JUNIOR et al., 2008).

Pesquisas referentes à emergência de plântulas de espécies frutíferas nativas são escassas, por isso objetivou-se, neste trabalho, avaliar o potencial germinativo de sementes de uvaia (Eugenia pyriformis) em diferentes substratos e teor de água.

\section{MATERIAL E MÉTODOS}

Os frutos de Eugenia pyriformis Cambess. foram colhidos diretamente de oito plantas- matriz localizadas no Estado de Mato Grosso do Sul, entre as coordenadas geográficas S 2302'37" e W 5509' 10" (MATO GROSSO DO SUL, 1990), na segunda quinzena de outubro de 2010. Os frutos foram processados em água corrente, retirando-se a polpa e selecionando-se as sementes inteiras e sem sinais de injúria, enquanto as sementes foram deixadas em temperatura ambiente, sobre papeltoalha, no Laboratório de Nutrição e Metabolismo de Plantas da Universidade Federal do Mato Grosso do Sul (UFGD), para secagem superficial por dois dias.

O solo utilizado para preparar os substratos foi coletado na região de Dourados, MS, o qual é classificado como Latossolo Vermelho Distroférrico, sendo a semeadura realizada em tubetes de 50 x $190 \mathrm{~mm}$, nos seguintes substratos: areia (A), latossolo + areia $(\mathrm{L}+\mathrm{A})(1: 1)$, latossolo + areia + cama de frango semidecomposta $(\mathrm{L}+\mathrm{A} 1+\mathrm{CF})(1: 1: 0,5)$, latossolo + areia + cama de frango semidecomposta $(\mathrm{L}+\mathrm{A} 2+\mathrm{CF})$ $(1: 2: 0,5)$ e latossolo + Bioplant ${ }^{\circledR}(\mathrm{L}+\mathrm{B})(1: 1)$.

Todos os substratos foram secos ao ar livre e passados em peneira de $2 \mathrm{~mm}$ de malha antes das misturas das frações, cujos recipientes foram mantidos em casa de vegetação com telado plástico, para redução da luminosidade em 50\%. Os níveis de irrigação avaliados foram de 25, 50, 75 e 100\% da capacidade de retenção de água (CRA), determinada adotando-se o conteúdo de água retida pelo solo após o escoamento de cada substrato (SOUZA et al., 2000).

As variáveis avaliadas foram a porcentagem de emergência de plântulas, tempo médio (TME) e índice de velocidade de emergência (IVE), empregando-se a fórmula de Maguire, sugerida por Vieira e Gusmão (2008).

Aos 60, 90, 120 e 150 dias de idade, as mudas foram avaliadas quanto ao número de folhas (NF); diâmetro do coleto (DC - cm), com o auxílio de paquímetro digital a $1 \mathrm{~cm}$ acima do nível do substrato; área foliar, com o auxílio do integrador de área foliar LCI3000 (AF - $\left.\mathrm{cm}^{2}\right)$; comprimento da parte aérea $(\mathrm{CPA}-\mathrm{cm})$ e de raiz ( $\mathrm{CR}-\mathrm{cm}$ ), com o auxílio de régua milimetrada; e massa seca de raízes (MSR - gr) e de folhas (MSF - gr) após a secagem do material em estufa de circulação de ar forçada a $60^{\circ} \mathrm{C}$ até peso constante, obtido em balança de precisão.

O delineamento estatístico adotado foi o inteiramente casualizado. Para avaliar a emergência, o esquema foi de parcela subdividida, sendo a parcela constituída por cada um dos cinco substratos e a subparcela, por cada um dos quatro níveis de irrigação, em quatro repetições de 20 tubetes com uma semente cada. Com relação ao crescimento das mudas, o esquema foi de parcela subsubdividida, em que a parcela constituiu cada um dos cinco substratos, a subparcela cada um dos três regimes hídricos (50, 75 e $100 \%$ CRA) e a subsubparcela cada idade das mudas, em quatro repetições de 20 mudas cada.

Os dados de porcentagem de emergência foram transformados para arcosseno (SNEDECOR, 1962) e os resultados, submetidos à análise de variância. Havendo diferença significativa, as médias referentes aos substratos foram comparadas pelo teste de Tukey, enquanto aquelas da capacidade de retenção de água, ajustadas por análise de regressão, ambas a $5 \%$ de probabilidade, sendo as análises realizadas pelo programa computacional SANEST (ZONTA et al., 1985). 


\section{RESULTADOS}

Entre substratos e níveis de água foi observada interação significativa $(\mathrm{p}<0,05)$ nas avaliações de emergência. A porcentagem e índice de velocidade de emergência foram maiores quando a semeadura ocorreu no substrato latossolo + Bioplant ${ }^{\circledR}(1: 1)$ e latossolo + areia $\mathrm{L}+\mathrm{A}+\mathrm{CF}$ 1:1:0,5 e 1:2:0,5, todos na capacidade de retenção de água de $75 \%$, enquanto na menor capacidade de retenção de água essas características foram maiores no substrato areia (Figura 1ab).

O menor tempo médio de emergência foi observado no substrato latossolo + areia + cama de frango semidecomposta $(1: 2: 0,5)$ a $75 \%$ da capacidade de retenção de água, e esse tempo foi próximo ao observado na emergência do substrato latossolo + areia + cama de frango semidecomposta $(1: 1: 0,5)$ a $50 \%$ da capacidade de retenção de água, ambos com início de emergência aos 40 dias, em média (Figura 1c).

Os dados referentes ao tratamento $25 \%$ de capacidade de retenção de água não foram considerados nas avaliações de crescimento das mudas porque proporcionaram baixa emergência de plântulas com crescimento reduzido, não entrando na análise estatística.

Não foi observada interação tripla significativa entre os tratamentos em nenhuma das variáveis avaliadas, entretanto houve interação significativa entre os substratos com os níveis de água e entre os substratos e níveis de água com a idade das mudas.

Os maiores número de folhas e área foliar foram observados nas mudas cultivadas com cama de frango em capacidade de retenção de água de $50 \%$, sendo essas condições de cultivo as que proporcionaram maior incremento dessa característica durante as avaliações (Tabela 1 e Figura 2cdf). O diâmetro das mudas não variou significativamente entre as capacidades de retenção de água em cada substrato de cultivo, exceto em areia, que foi maior a 50\% de capacidade de retenção de água (Figura 2ab).

As mudas no substrato latossolo + areia + cama de frango apresentaram maior comprimento de parte aérea; ao final das avaliações, a parte aérea foi maior na capacidade de retenção de água de $100 \%$ (Tabela 2 e Figuras $3 \mathrm{ab}$ ). O maior crescimento radicular foi observado no substrato areia a $100 \%$ da capacidade de retenção de água e latossolo + areia 100 e $50 \%$ da capacidade de retenção de água (Tabela 2). a)
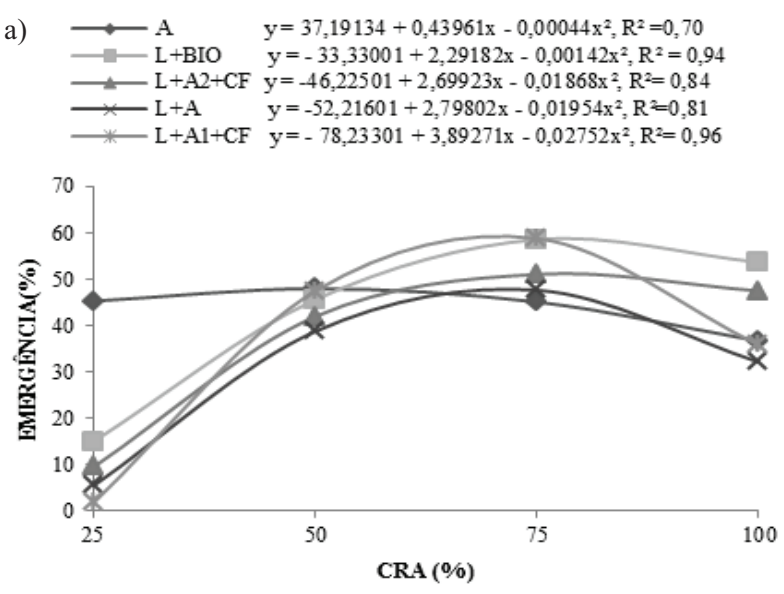

b) - A $\quad \mathrm{y}=0,06582+0,00341 \mathrm{x}+0,00032 \mathrm{x}^{2}, \mathrm{R}^{2}=0,96$ $\begin{array}{ll}- \text { L+BIO } & y=-0,14262+0,00851 x-0,00005 x^{2}, R^{2}=0,93 \\ -L+A 2+C F & y=-0,20181+0,01121 x-0,00008 x^{2}, R^{2}=0,81\end{array}$ - $\mathrm{L}+\mathrm{A} \quad \mathrm{y}=0,16801+0,00862 \mathrm{x}-0,00005 \mathrm{x}^{2}, \mathrm{R}^{2}=0,94$ $-\mathrm{L}+\mathrm{A} 1+\mathrm{CF} \quad \mathrm{y}=-0,23902+0,01171 \mathrm{x}-0,00008 \mathrm{x}^{2}, \mathrm{R}=0,99$

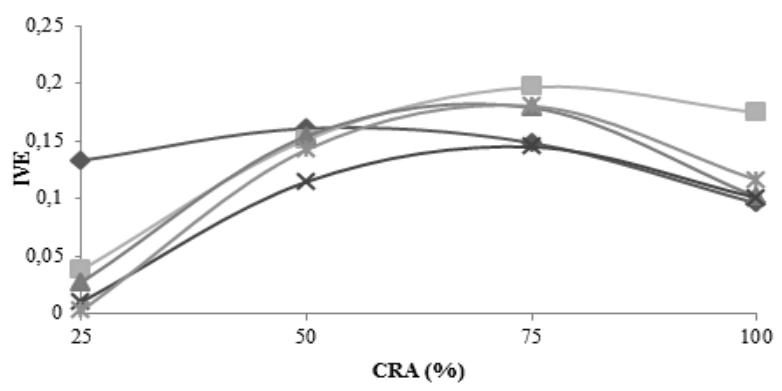

c)
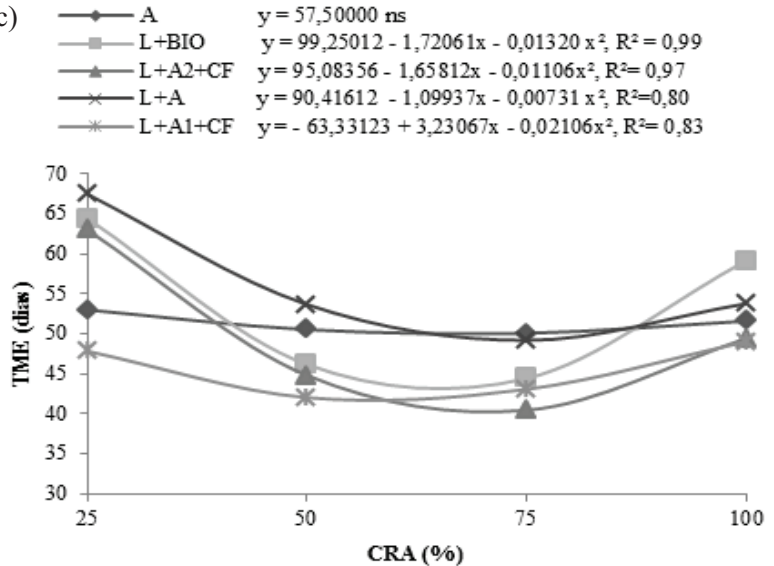

Figura 1 - Porcentagem de emergência (a), índice de velocidade de emergência (b) e tempo médio de emergência (c) de sementes de E. pyriformis em razão da capacidade de retenção de água (CRA) e substratos.

Figure 1 - Percentage of emergency $(a)$, the speed index of emergence $(b)$ and average time of emergency (c) of E. pyriformis seeds according to water retention capacity (WHC) and substrates.

Revista Árvore, Viçosa-MG, v.37, n.1, p.49-58, 2013 
Tabela 1 - Número de folhas (NF), área foliar (AF) e diâmetro do coleto de mudas de E. pyriforms em razão de diferentes substratos e capacidade de retenção de água (CRA).

Table 1 - Number of leaves $(N F)$, leaf area $(A F)$ and collar diameter $(C D)$ of $\mathrm{E}$. pyriformis seedlings as a function of substrate and water retention capacity $(W R C)$.

\begin{tabular}{|c|c|c|c|c|}
\hline Substrato & CRA $(\%)$ & $\mathrm{NF}$ & $\mathrm{AF}\left(\mathrm{cm}^{2}\right)$ & $\mathrm{DC}(\mathrm{cm})$ \\
\hline \multirow{3}{*}{ Areia } & 50 & $8 \mathrm{Ab}$ & 32,24 Ac & 3,13 Aa \\
\hline & 75 & $7 \mathrm{Ab}$ & $32,30 \mathrm{Ab}$ & $2,49 \mathrm{Bab}$ \\
\hline & 100 & $5 \mathrm{Bc}$ & $29,99 \mathrm{Ab}$ & $2,45 \mathrm{Bab}$ \\
\hline \multirow{3}{*}{ Latossolo + Bioplant $®(L+B)$} & 50 & $8 \mathrm{Bb}$ & $47,72 \mathrm{Ab}$ & $2,90 \mathrm{Aa}$ \\
\hline & 75 & $10 \mathrm{Aa}$ & $49,37 \mathrm{Aa}$ & $2,62 \mathrm{Aa}$ \\
\hline & 100 & $8 \mathrm{Ba}$ & $51,57 \mathrm{Aa}$ & $2,74 \mathrm{Aa}$ \\
\hline \multirow{3}{*}{ Latossolo+areia + cama de frango $(\mathrm{L}+\mathrm{A} 2+\mathrm{CF})$} & 50 & $9 \mathrm{Aa}$ & $67,83 \mathrm{Aa}$ & $2,94 \mathrm{Aa}$ \\
\hline & 75 & 9 Aa & $50,39 \mathrm{Ba}$ & $2,80 \mathrm{Aa}$ \\
\hline & 100 & $8 \mathrm{Ba}$ & $52,57 \mathrm{Ba}$ & $2,77 \mathrm{Aa}$ \\
\hline \multirow{3}{*}{ Latossolo+areia $(\mathrm{L}+\mathrm{A})$} & 50 & $8 \mathrm{Ab}$ & $40,0 \quad \mathrm{Abc}$ & $2,32 \mathrm{Ab}$ \\
\hline & 75 & 9 Aa & $38,29 \mathrm{Ab}$ & $2,48 \mathrm{Aab}$ \\
\hline & 100 & $7 \mathrm{Bb}$ & $29,11 \mathrm{Bb}$ & $2,30 \mathrm{Ab}$ \\
\hline \multirow{3}{*}{ Latossolo+areia +cama de frango (L+A1+CF) } & 50 & $9 \mathrm{Aa}$ & $68,14 \mathrm{Aa}$ & $2,37 \mathrm{Ab}$ \\
\hline & 75 & $9 \mathrm{Aa}$ & $37,80 \mathrm{Bb}$ & $2,26 \mathrm{Ab}$ \\
\hline & 100 & $7 \mathrm{Bb}$ & $37,74 \mathrm{Bb}$ & $2,30 \mathrm{Ab}$ \\
\hline CV (\%) & & 14,2 & 20,0 & 11,8 \\
\hline
\end{tabular}

Tratamentos com médias não seguidas pela mesma letra maiúscula diferem entre os níveis de capacidade de retenção de água para o mesmo substrato, e letra minúscula difere no nível de capacidade de retenção de água entre os diferentes substratos, pelo teste de Tukey a 5\% de erro.

Tabela 2 - Comprimento da parte aérea (CPA), comprimento de raiz (CR), massa seca de raiz (MSR) e massa seca de folha (MSF) de mudas de uvaia (Eugenia pyriforms) em razão de diferentes substratos e capacidade de retenção de água (CRA).

Table 2 - Length of the shoot (LS), root length (RL), root dry weight (RDW) and leaf dry mass (MSF) of E. pyriforms seedlings as a function of substrate and water retention capacity (WRC).

\begin{tabular}{|c|c|c|c|c|c|}
\hline Substrato & CRA $(\%)$ & $\mathrm{CPA}(\mathrm{cm})$ & $\mathrm{CR}(\mathrm{cm})$ & $\operatorname{MSR}(\mathrm{g})$ & $\operatorname{MSF}(\mathrm{g})$ \\
\hline \multirow{3}{*}{ Areia } & 50 & $13,01 \mathrm{Ad}$ & $14,22 \mathrm{Aab}$ & $0,49 \mathrm{Aa}$ & $0,18 \mathrm{Ab}$ \\
\hline & 75 & $13,88 \mathrm{Ac}$ & $13,19 \mathrm{Aab}$ & $0,46 \mathrm{Aa}$ & $0,18 \mathrm{Abc}$ \\
\hline & 100 & $12,84 \mathrm{Ab}$ & $15,26 \mathrm{Aa}$ & $0,32 \mathrm{Ba}$ & $0,15 \mathrm{Ac}$ \\
\hline \multirow{3}{*}{ Latossolo+ Bioplant ${ }^{\circledR}(\mathrm{L}+\mathrm{B})$} & 50 & $17,76 \mathrm{Abc}$ & $12,17 \mathrm{Bb}$ & $0,38 \mathrm{Aab}$ & $0,27 \mathrm{ABab}$ \\
\hline & 75 & $17,87 \mathrm{Aa}$ & $15,08 \mathrm{Aa}$ & $0,25 \mathrm{Bbc}$ & $0,33 \mathrm{Aa}$ \\
\hline & 100 & 19,44 Aa & $12,22 \mathrm{Bb}$ & $0,26 \mathrm{Bab}$ & $0,26 \mathrm{Bb}$ \\
\hline \multirow{4}{*}{ Latossolo+areia + cama de frango $(\mathrm{L}+\mathrm{A} 2+\mathrm{CF})$} & 50 & $19,17 \mathrm{Ab}$ & $12,17 \mathrm{Bab}$ & 0,42 Aab & $0,36 \mathrm{Aa}$ \\
\hline & 75 & $16,31 \mathrm{Bab}$ & $15,08 \mathrm{Aa}$ & $0,31 \mathrm{Bb}$ & $0,27 \mathrm{Bab}$ \\
\hline & 100 & $20,07 \mathrm{Aa}$ & $12,22 \mathrm{Bb}$ & $0,30 \mathrm{Bab}$ & 0,37 Aa \\
\hline & 50 & $16,07 \mathrm{Ac}$ & $15,53 \mathrm{Aa}$ & $0,22 \mathrm{Ac}$ & $0,31 \mathrm{Aa}$ \\
\hline \multirow[t]{2}{*}{ Latossolo+areia(L+A) } & 75 & $14,89 \mathrm{ABbc}$ & $14,06 \mathrm{Aab}$ & $0,29 \mathrm{Ab}$ & $0,22 \mathrm{Bbc}$ \\
\hline & 100 & $13,46 \mathrm{Bb}$ & $15,17 \mathrm{Aa}$ & $0,21 \mathrm{Aab}$ & $0,19 \mathrm{Bbc}$ \\
\hline \multirow{3}{*}{ Latossolo+areia +cama de frango $(\mathrm{L}+\mathrm{A} 1+\mathrm{CF})$} & 50 & $21,63 \mathrm{Aa}$ & $13,15 \mathrm{ABab}$ & $0,36 \mathrm{Ab}$ & $0,30 \mathrm{Aa}$ \\
\hline & 75 & $14,51 \mathrm{Bbc}$ & $11,61 \mathrm{Bb}$ & $0,17 \mathrm{Bc}$ & $0,15 \mathrm{Bc}$ \\
\hline & 100 & $14,36 \mathrm{Bb}$ & $14,47 \mathrm{Aab}$ & $0,18 \mathrm{Bb}$ & $0,20 \mathrm{Bbc}$ \\
\hline $\mathrm{CV}(\%)$ & & 12,514 & 18,103 & 28,896 & 26,251 \\
\hline
\end{tabular}

Tratamentos com médias não seguidas pela mesma letra maiúscula diferem entre os níveis de capacidade de retenção de água no mesmo substrato, e letra minúscula difere no nível de capacidade de retenção de água entre os diferentes substratos, pelo teste de Tukey a $5 \%$ de erro.

Revista Árvore, Viçosa-MG, v.37, n.1, p.49-58, 2013 
a)
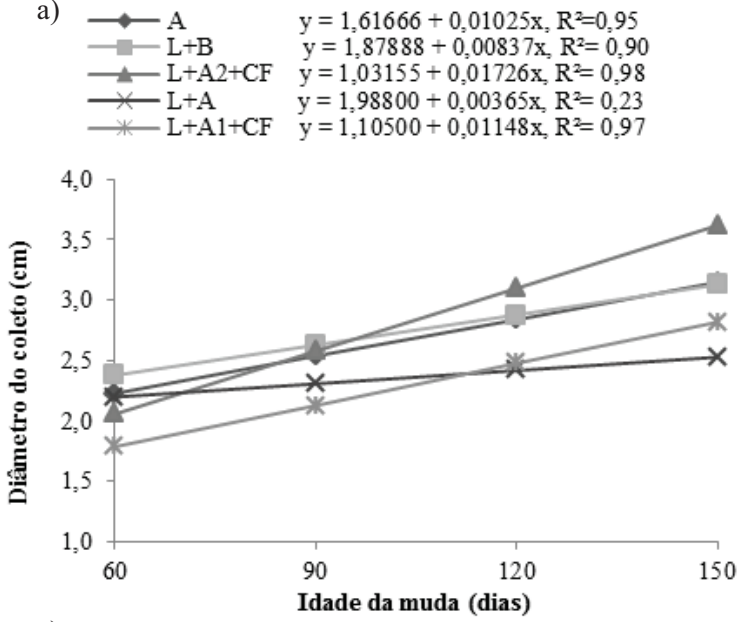

c)
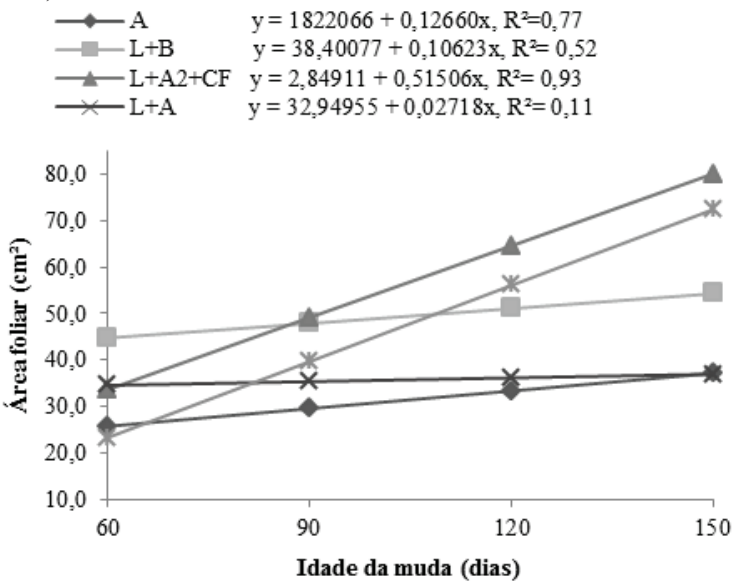

b)
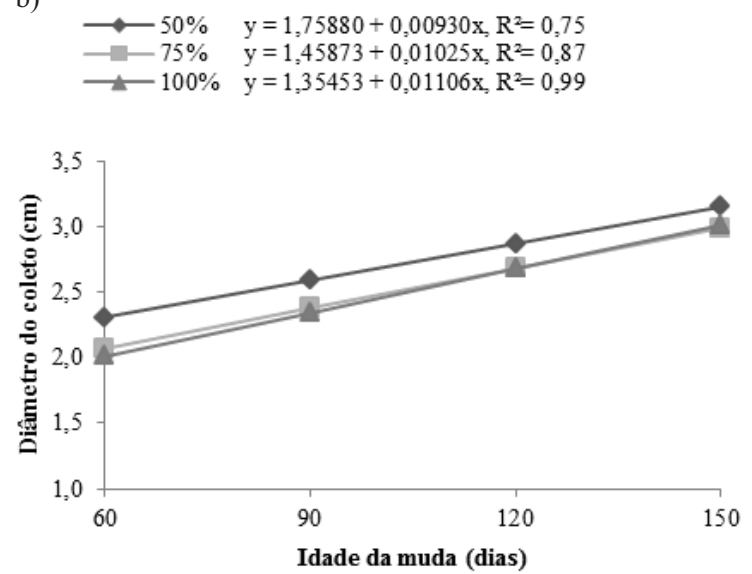

d)
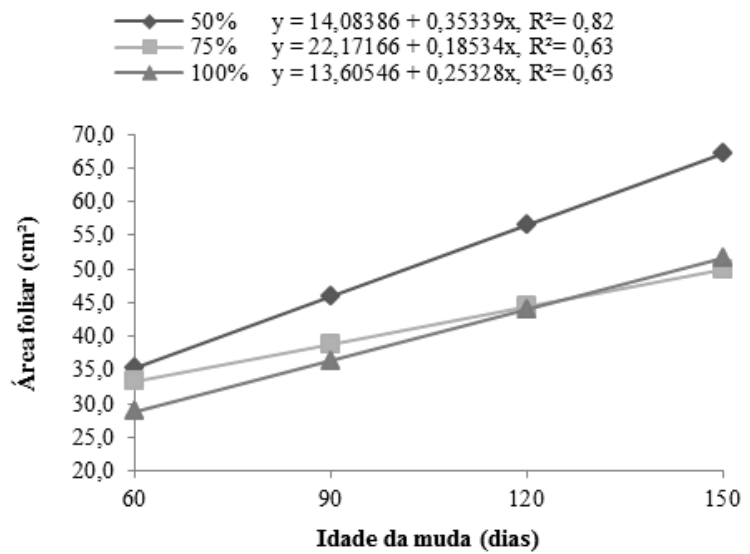

e)
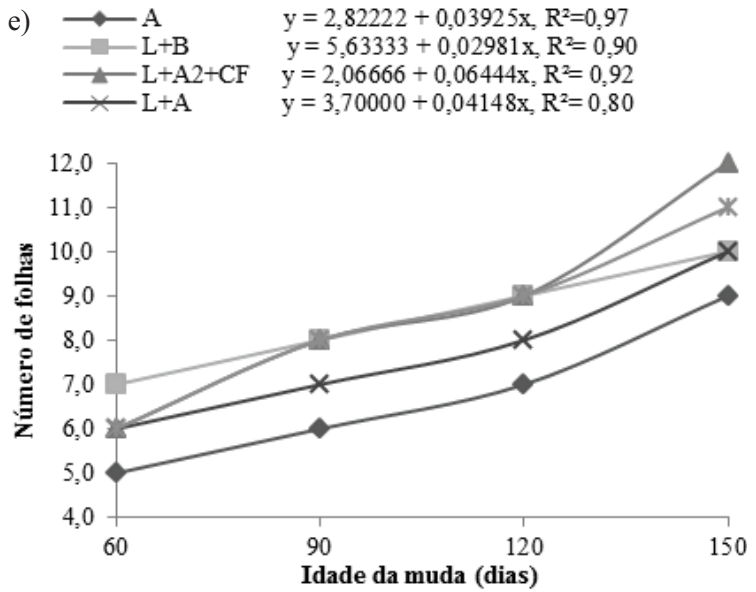

Figura 2 - Diâmetro do coleto, área foliar e número de folhas de mudas de E. pyriforms em diferentes idades, em razão do substrato (a, c, e) e retenção de água (b, d).

Figure 2-Collar diameter; leaf area anD number of leaves of $\mathrm{E}$. pyriformis seedlings at different ages as a function of substrate $(a, c, e)$ and water retention $(b, d)$. 

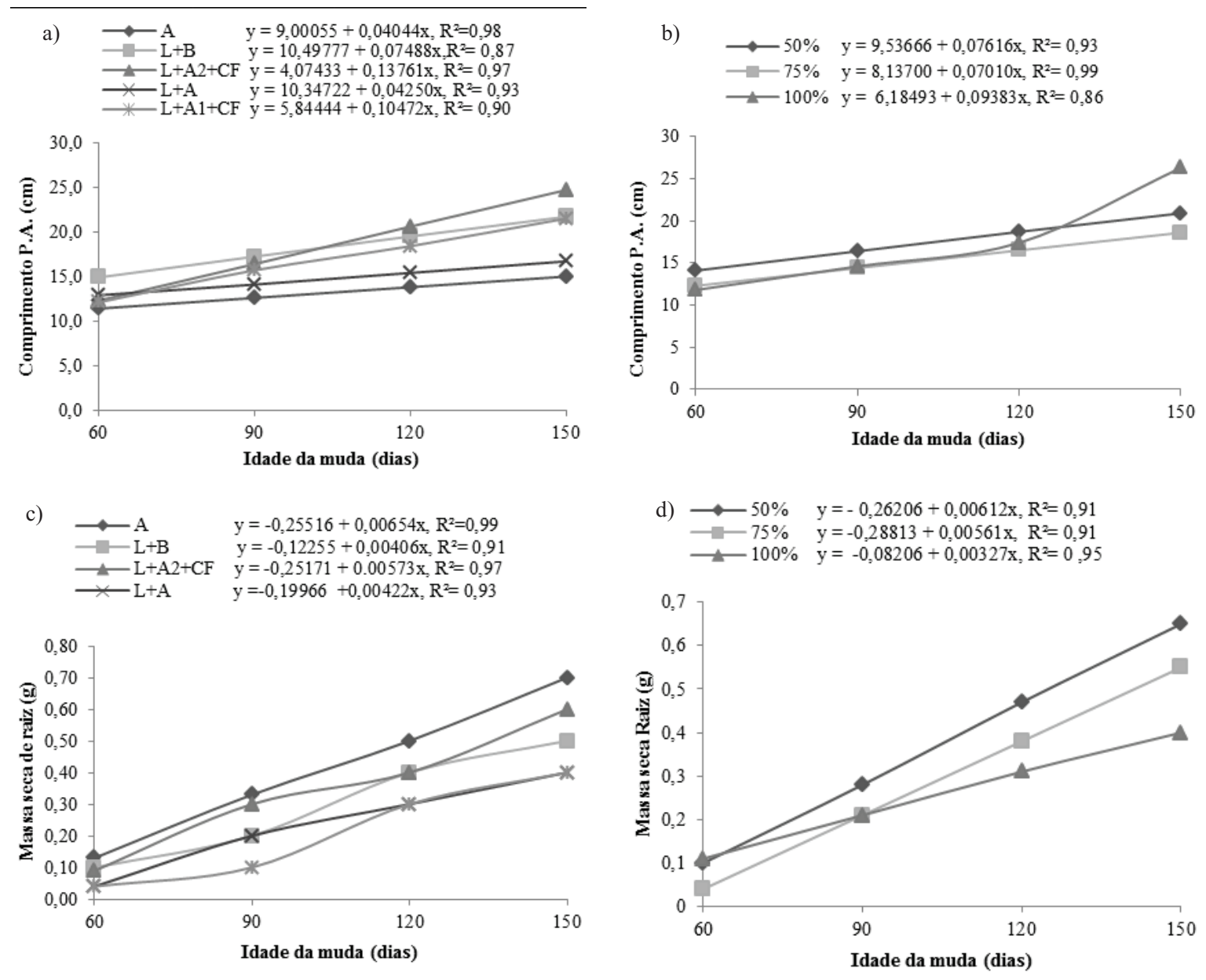
e) $\longrightarrow \mathrm{A} \quad \mathrm{y}=0,01120+0,00155 \mathrm{x}, \mathrm{R}^{2}=0,99$ - L $+\mathrm{B}-\quad \mathrm{y}=0,06867+0,00210 \mathrm{x}, \mathrm{R}^{2}=0,92$ $-\mathrm{L}+\mathrm{A} 2+\mathrm{CF} \mathrm{y}=-0,21044+0,00523 \mathrm{x}, \mathrm{R}^{2}=0,94$ $\longrightarrow \mathrm{L}+\mathrm{A}-\mathrm{y}=-0,09111+0,00316 \mathrm{x}, \mathrm{R}^{2}=0,86$
$-\mathrm{L}+\mathrm{A} 1+\mathrm{CF} \mathrm{y}=-0,12377+0,00331 \mathrm{x}, \mathrm{R}^{2}=0,90$
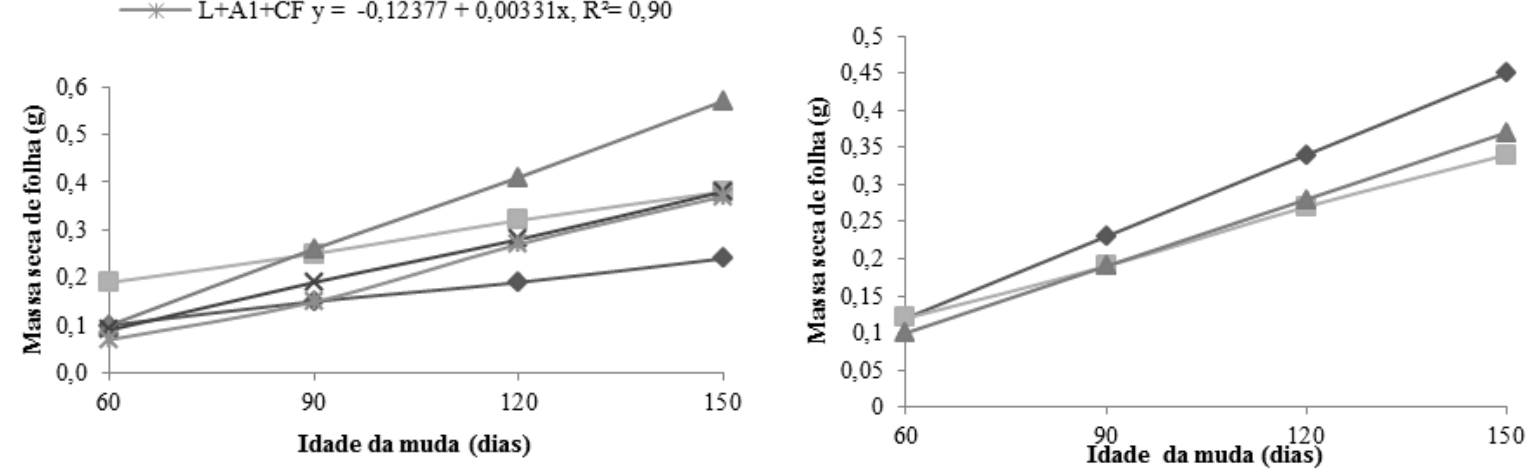

Figura 3 - Comprimento de parte aérea, massa seca da raiz e de folha de mudas de E. pyriformis em diferentes idades, em razão de substratos (a, c, e) e capacidade de retenção de água (b, d, f).

Figure 3 - Length of the shoots; root and leaf dry mass of $\mathrm{E}$. pyriformis seedlings at different ages as a function of substrate $(a, c, e)$ and water retention $(b, d, f)$.

Revista Árvore, Viçosa-MG, v.37, n.1, p.49-58, 2013 
A massa seca das raízes foi maior nas mudas cultivadas em areia na capacidade de retenção de água de 50 e $75 \%$, entretanto a massa seca de folhas foi maior quando estas foram cultivadas em latossolo + areia + cama de frango (1:2:0,5) a $50 \%$ da capacidade de retenção de água (Tabela 2 e Figura 3c-f). Assim, todos os resultados indicaram que os substratos e níveis de água avaliados não impediram o desenvolvimento das mudas, que podem continuar por mais tempo nas mesmas condições, pois, por todos os resultados das Figuras 2 e 3, se observou crescimento linear em relação à idade da muda.

\section{DISCUSSÃO}

Os maiores valores de germinação obtidos neste trabalho encontram-se próximos aos observados por Scalon et al. (2012) com sementes da mesma espécie quando semeadas sobre areia e postas em condições controladas $\left(20-30^{\circ} \mathrm{C}\right)$, cujos valores de germinação ficaram entre 77 e $57 \%$, sugerindo, assim, que a porcentagem final de germinação observada é um padrão genético da espécie e que os melhores tratamentos proporcionaram a expressão desse padrão.

Resultados semelhantes quanto ao substrato também ocorreram em sementes de araçá (Psidium guineense Swartz) submetidas a diferentes substratos e regimes hídricos, cuja maior porcentagem de germinação foi no substrato latossolo + areia (1:1) na capacidade de retenção de 75\% (GONÇALVES et al., 2009), reforçando que esse nível de água foi adequado também para sementes de outras espécies, assim como o efeito benéfico da adição de matéria orgânica no substrato.

Na literatura, observou-se que um dos efeitos benéficos da adição de matéria orgânica ou areia no substrato é a melhoria na drenagem e, consequentemente, na aeração do substrato, o que também pode ser atribuído aos resultados da pesquisa com a adição de areia ou Bioplant®. Em substrato contendo matéria orgânica, também foram observados maiores porcentagem e índice de velocidade de emergência em mudas de pau-ferro (Caesalpinia ferrea) (SCALON et al., 2011) e de mangabeira (Hancornia speciosa Gomes) (SILVA et al., 2009).

A capacidade de retenção de água de $100 \%$ pode ter prejudicado a aeração, causando, assim, estresse por excesso de água, pois, embora a absorção de água seja necessária para a ativação de processos metabólicos das sementes, desencadeando uma sucessão de eventos, que culminam com a emissão da raiz primária (KOS; POSCHLOD, 2008), em solos encharcados ou excessivamente úmidos. As limitações à difusão do oxigênio também podem provocar a paralisação da germinação, provavelmente porque a ausência ou escassez de oxigênio favorece a produção de etanol nas células, que é tóxico ao metabolismo normal por provocar acidificação e morte das sementes (KOLB; JOLY, 2010). Entretanto, em condições de umidade abaixo do exigido pela espécie verifica-se redução da atividade enzimática, culminando com a baixa porcentagem e velocidade de germinação das sementes (BEWLEY; BLACK, 1994).

Os extremos de disponibilidade hídrica proporcionaram maior tempo médio de emergência, o que não é um resultado desejável, uma vez que expõe a semente a fatores adversos por tempo maior. Assim, quanto menor o tempo médio de emergência, mais rapidamente a plântula se estabelece como indivíduo autotrófico, com possibilidade de crescimento mais rápido.

Quanto ao elevado número de dias para iniciar a germinação, observou-se, na literatura, que as sementes de outras frutíferas nativas do Cerrado também demoram para iniciar o processo germinativo, sendo o tempo médio de germinação de sementes de araçá (Psidium guineensi Swartz.) de 52 dias. Em sementes de marmelo (Alibertia edulis (Rich.) A. Rich. ex DC), esse tempo foi de 28 dias; nas de uvaia (Eugenia pyriformis Camb.), 66 dias (NEVES, 2011); e nas sementes de cagaita (Eugenia dysenterica DC), o período de estabilização da emergência foi de 103 dias (SOUZA et al., 2002).

O maior crescimento da área foliar na capacidade de retenção de água de 50\%, comparado a 75 e 100\%, sugeriu que essa condição de menor disponibilidade de água foi satisfatória nas mudas de uvaia ( $E$. pyriformis). Através de informações da literatura, observase que, durante o crescimento de mudas submetidas a excesso de água, pode ocorrer acúmulo de ACC (ácido 1-aminociclopropano-1-carboxílico) nas raízes e seu transporte para a parte aérea, onde é convertido a etileno, cujo acúmulo deste nessa região provoca senescência e abscisão precoce das folhas (TAIZ; ZEIGER, 2009), o que pode refletir em menor área foliar das plantas.

Revista Árvore, Viçosa-MG, v.37, n.1, p.49-58, 2013 
Resultados semelhantes de redução da área foliar em mudas também foram observados por Lenhard et al. (2010) em pau-ferro (Caesalpinea ferrea), em razão dos dias de exposição ao excesso de água, embora o crescimento da área foliar dessas mudas tenha ocorrido até os 35 dias alagadas, mas foi muito inferior ao daquelas cultivadas com 40 e $75 \%$ da capacidade de retenção.

Os maiores comprimentos da parte aérea obtidos nos tratamentos em que se utilizou cama de frango estão de acordo com Graciano et al. (2006), quando relataram que o uso de resíduos orgânicos deverá estimular, especialmente no início do ciclo da cultura, o desenvolvimento adequado da parte aérea, em termos de altura e área foliar. Segundo Vieira e Casali (1997), os resíduos orgânicos poderão ter efeito benéfico até mesmo se forem usados como cobertura do solo, especialmente naqueles de Cerrado muito intemperizados e com baixo teor de matéria orgânica, uma vez que são sujeitos ao aquecimento e dessecamento da camada superficial.

Mesmo com maior crescimento radicular a $50 \mathrm{e}$ $100 \%$ da capacidade de retenção de água em latossolo + areia, bem como $100 \%$ em areia, a massa seca foi maior a 50 e $75 \%$ da capacidade de retenção de água em areia, sugerindo que a condição de $50 \%$ da capacidade de retenção de água não representou condição de déficit hídrico das mudas dessa espécie. Em condição de déficit hídrico ocorre redução no crescimento da parte aérea e inibição da expansão foliar, enquanto proporção maior de assimilados é direcionada para sustentar o crescimento das raízes, levando a um crescimento preferencial delas em direção a zonas do solo que permanecem úmidas (TAIZ; ZEIGER, 2009). Entretanto, o excesso de água no solo leva à respiração anaeróbia das raízes, que têm como produtos finais o ácido lático e o etanol, causadores da morte das células radiculares por acidose e, com isso, há menor crescimento radicular e menor absorção de água e nutrientes (FLOSS, 2008). Assim, o maior crescimento radicular das mudas de uvaia observado tanto a 50 quanto a $100 \%$ de capacidade de retenção de água demonstra comportamento tolerante dessa espécie tanto à menor quanto à maior disponibilidade de água no substrato.

O uso da cama de frango no solo proporcionou maior desenvolvimento das plantas, provavelmente por favorecer a maior turgidez das raízes, além reduzir a perda de nutrientes por lixiviação e melhorar os atributos físicos, químicos e microbiológicos do solo (CARVALHO et al., 2005). Os resultados obtidos para uvaia ( $E$. pyriformis) sugerem que nessa fase inicial de produção das mudas é interessante investir em substrato, entretanto não se pode generalizar sobre a necessidade de matéria orgânica para a produção de mudas de todas as espécies, pois Paiva Sobrinho et al. (2010) observaram que as mudas de mangaba (Hancornia speciosa Gomes), baru (Dipteryx alata Vog.) e cagaita (Eugenia dysenterica D.C.), espécies nativas do Cerrado, desenvolveram-se melhor em solo desprovido de qualquer fonte de matéria orgânica. Diante desses resultados, percebe-se que, apesar de muitas espécies ocuparem o mesmo bioma e estarem submetidas a condições semelhantes, certas especificidades e exigências podem ser diferenciadas.

Observa-se, dessa forma, que a maior porcentagem de emergência das plântulas foi no substrato latossolo + Bioplant® (1:1) e latossolo + areia + cama de frango nas duas variações avaliadas, bem como nas capacidades de retenção de água de 50 ou $75 \%$; no entanto, o desenvolvimento das mudas foi maior no substrato latossolo + areia + cama de frango (1:2:0,5), na capacidade de retenção de água de $50 \%$.

Considerando o custo-benefício, a adição de cama de frango em comparação com o uso de Bioplant ${ }^{\circledR}$ pode representar uma técnica de cultivo mais econômica e prática para os viveiristas, pois, além de fornecer destino para dejetos provenientes da avicultura, esse dejeto é encontrado com facilidade, sendo de baixo custo se comparado à aquisição do Biolant ${ }^{\circledR}$. Em relação ao uso de $50 \%$ da capacidade de retenção de água, a economia de água para a produção de mudas representa menor custo de produção, além da economia desse recurso hídrico.

\section{CONCLUSÃO}

Para otimizar a emergência das plântulas e o crescimento das mudas de uvaia (E. pyriformis), devese utilizar o substrato latossolo + areia + cama de frango (1:2:0,5) a 50\% da capacidade de retenção de água.

\section{REFERENCIAS}

ANDRADE, R. N. B.; FERREIRA, A. G.

Germinação e armazenamento de sementes de uvaia (Eugenia pyriformis Camb.) - Myrtaceae.

Revista Brasileira de Sementes, v.22, n.2, p.118-125, 2000. 
BEWLEY, J. D.; BLACK, M. Seeds: physiology of development and germination. New York: Plenum, 1994. 445p.

CARVALHO, J. E. et al. Cobertura morta do solo no cultivo de alface cv. Regina 2000, em Ji-Paraná/ RO. Ciência e Agrotecnologia, v.29, n.5, p.935-939, 2005.

DELGADO, L. F.; BARBEDO, C. J. Tolerância à dessecação de sementes de Eugenia.

Pesquisa Agropecuária Brasileira, v.42, n.2, p.265-272, 2007.

FLOSS, E. Fisiologia das plantas cultivadas: o estudo que está por trás do que se vê. 4.ed. Passo Fundo: UPF, 2008. 733p.

GONÇALVES, C. A. R. L. et al. Germinação de araçá (Psidium guineense Swartz) em diferentes substratos e regimes hídricos. In: CONGRESSO BRASILEIRO DE SEMENTES, QUALIDADE: DESAFIO PERMANENTE, 16. 2009, londrina; Informativo ABRATES, v. 19, n.2, p. $237,2009$.

GRACIANO, J. D. et al. Efeito da cobertura do solo com cama-de-frango semidecomposta sobre dois clones de mandioquinha-salsa. Acta Scientiarum Agronomy, v.28, n.3, p.367-376, 2006.

KOLB, R. M.; JOLY, C. A. Germination and anaerobic metabolism of seeds of Tabebuia cassinoides (Lam.) DC subjected to flooding and anoxia. Flora, v.205, n.2, p.112-117, 2010.

KOS, M.; POSCHLOD, P. Correlates of interspecific variation in germination response to water stress in a semi-arid savannah. Basic and Applied Ecology, n.9, p.645-652, 2008.

LEHN, C. R.; ALVES, F. M.; DAMASCENO JÚNIOR, G. A. Florística e fitossociologia de uma área de Cerrado Sensu stricto na região da borda oeste do Pantanal, Corumbá, MS, Brasil.

Pesquisas Botânica, n.59, p.129-142, 2008.

LENHARD, N. R.; SCALON, S. P. Q.; NOVELINO, J. O. Crescimento inicial de mudas de pau ferro sob diferentes regimes hídricos. Ciência e Agrotecnologia, v.34, n.4, p.870-877, 2010.
MAGUIRE, J. D. Speed of germination aid in selection and evaluation for seedling emergence and vigor. Crop Science, v.2, n.2, p.176-177, 1962.

MATO GROSSO DO SUL. Secretaria do Planejamento e Coordenação Geral. Atlas Multireferencial. Campo Grande: 1990. 28p.

NEVES, E. M. S. Dessecação, armazenamento e condicionamento osmótico em sementes de espécies frutíferas do cerrado. 2011. 79f. Dissertação (Mestrado em Agronomia) Faculdade de Ciências Agrárias, Universidade Federal da Grande Dourados, 2011.

PAIVA SOBRINHO, S. et al. Substratos na produção de mudas de três espécies arbóreas do cerrado. Agrária, v.5, n.2, p.238-243, 2010 .

REISSER JUNIOR, C.; MEDEIROS, C. A. B.; RADIN, B. Produção de mudas em estufas plásticas. Pelotas: Embrapa Clima Temperado, 2008. 5p. Disponível em: <http:// www.cpact.embrapa.br/imprensa/artigos/2008/ artigo\%20Reisser_alface.pdf $>$. Acesso em: 20 jul. 2011.

RODRIGUES, A. C. C. et al. Efeito do substrato e luminosidade na germinação de Anadenanthera colubrina. Revista Árvore, v.31, n.2, p.187193, 2007.

SCALON, S. P. Q. et al. Germinação e crescimento de Caesalpinia ferrea Mart. ex Tul. em diferentes substratos. Revista Árvore, v.35, n.3, p.633-639, 2011.

SCALON, S. P. Q. et al. Sensibilidade à dessecação e ao armazenamento em sementes de Eugenia pyriformis Cambess. (uvaia). Revista Brasileira de Fruticultura, v.34, n.1, p.269-276, 2012.

SCREMIN-DIAS, E. (Org.). Produção de sementes de espécies florestais nativas. Campo Grande: Universidade Federal de Mato Grosso do Sul, 2006. 43p. (Série Rede de Sementes do Pantanal).

Revista Árvore, Viçosa-MG, v.37, n.1, p.49-58, 2013 
SILVA, E. A. et al. Efeito de diferentes substratos na produção de mudas de mangabeira (Hancornia speciosa). Revista Brasileira de

Fruticultura, v.31, n.3, p.925-929, 2009.

SNEDECOR, G. W. Statistical methods. Ames: Iowa State University Press, 1962. 422p.

SOUZA, C. C. et al. Avaliação de métodos de determinação de água disponível e manejo da irrigação em solo roxa sob cultivo de algodoeiro herbáceo. Revista Brasileira de Engenharia Agrícola e Ambiental, v.4, n.3, p.338-342, 2000.

SOUZA, E. B. et al. Crescimento e sobrevivência de mudas de cagaiteira (Eugenia dysenterica DC) nas condições de cerrado. Revista

Brasileira de Fruticultura, v.24, n.2, p.491-495, 2002.

TAIZ, L.; ZEIGER, E. Fisiologia vegetal. 3.ed. Porto Alegre: Artmed, 2009. 719p.
VENDRAME SILVA, C.; BILIA, D. A. C.;

BARBEDO, C. J. Fracionamento e germinação em sementes de Eugenia. Revista Brasileira de Sementes, v.27, n.1, p.86-92, 2005.

VIEIRA, F. A.; GUSMÃO, E. Biometria, armazenamento de sementes e emergência de plântulas de Talisia esculenta Radlk.

(Sapindaceae). Ciência e Agrotecnologia, v.32, n.4, p.1073-1079, 2008.

VIEIRA, M. C.; CASALI, V. W. D. Adaptação da cultura da mandioquinha-salsa à adubação orgânica. Informe Agropecuário, v.19, n.190, p.40-42, 1997.

ZONTA, E. F.; MACHADO, A. A.; SILVEIRA JUNIOR, P. Sistema de análise estatística (SANEST) para microcomputador (versão 1.0). In: SIMPÓSIO DE ESTATÍSTICA APLICADA À EXPERIMENTAÇÃO AGRONÔMICA, 1985, Piracicaba. Anais... Piracicaba: ESALQ, 1985. p.74-90. 